\title{
Low body mass index in long standing rheumatoid arthritis: relation to RA disease activity and functional indices
}

\author{
S.M. Gamal', A.K. Alkemary², M.A. Abdo', A.H.M. El Dakrony ${ }^{1}$ \\ ${ }^{1}$ Rheumatology and Rehabilitation Department, Faculty of Medicine, Cairo University; \\ 2Internal Medicine Department, Faculty of Medicine, Cairo University, Egypt
}

\begin{abstract}
SUMMARY
The aim of the work was to study the relationship between the body mass index (BMI) in longstanding rheumatoid arthritis (RA) and RA disease activity and functional indices.

This study included 105 RA patients. For all patients, we recorded the presence of erosions on radiographs, the presence of subcutaneous nodules (SCN), the 28-tender joint count (TJC), 28-swollen joint count (SJC) scores, the visual analogue scale (VAS), physicians' global assessments (PhGA), the erythrocyte sedimentation rate (ESR), and the rheumatoid factor (RF). The disease activity index (DAS28) and BMI were calculated and current treatment was recorded. Patients were divided into two groups: group I: BMI <25, and group II: BMI $>25$. Group I included $32(30.5 \%)$ patients, whereas group II included $73(69.5 \%)$ patients. There were statistically significant differences between the two groups regarding each of the following: $\mathrm{SJC}(\mathrm{p}=0.006)$, erosions ( $\mathrm{p}=0.006)$, DAS28 ( $\mathrm{p}=0.016)$ and PhGA ( $\mathrm{p}=0.007)$. All were higher in group I (underweight and normal) than in group II (overweight and obese). No statistically significant differences emerged regarding age $(\mathrm{p}=0.11)$, smoking ( $p=0.69)$, disease duration $(\mathrm{p}=0.46), \operatorname{TJC}(\mathrm{p}=0.14), \operatorname{SCN}(\mathrm{p}=1.00), \operatorname{HAQ}(\mathrm{p}=0.26), \operatorname{VAS}(\mathrm{p}=0.16), \operatorname{ESR}$ $(\mathrm{p}=0.25), \mathrm{RF}(\mathrm{p}=0.54)$ and steroid cumulative dose $(\mathrm{p}=0.08)$.

Low BMI in longstanding RA patients may indicate more active and erosive disease and it may be considered as a poor prognostic factor.
\end{abstract}

Key words: Rheumatoid arthritis; Body mass index; DAS28; Radiological erosions.

Reumatismo, 2018; 70 (2): $72-77$

\section{INTRODUCTION}

heumatoid arthritis (RA) is a chronic systemic autoimmune disorder in which polyarticular synovitis is particularly prominent (1). Although some studies have shown that high body mass index (BMI) may be associated with RA (2), and poor RA disease outcome (3), others have reported that there is a paradoxical effect of $B M I$ on survival in people with $R A$, demonstrating that as BMI decreases, so too does survival probability among RA patients studied (4).

It has been reported that obesity may have a protective effect on the amount of joint destruction in established RA (5), and that weight loss in individuals with RA has been recognized since early observations of the disease (6). It has also been found that low BMI at the beginning of RA is associated with higher radiographic progression (7). Low BMI among people with RA may indicate uncontrolled active systemic inflammation (8). Accordingly, BMI could be of interest as a sensitive and inflammation-independent predictor for the radiological outcome of RA (7).

On the other hand, the influence of BMI and/or body fat on RA and its disease activity is not entirely clear, since there have been conflicting results (2) and other researchers have concluded that there is no association between BMI and disease activity composites of RA (9).

This study aimed to explore the relationship between BMI in longstanding RA and RA prognostic factors. 


\section{PATIENTS AND METHODS}

A cross-sectional study was conducted involving 105 RA patients (96 women and 9 men). Patients were diagnosed according to the 1987 ACR criteria for RA (10). Patients were recruited from the Rheumatology and Rehabilitation department, Cairo University hospital. Their age ranged from 22 years to 66 years with a mean of $45.92 \pm 12.12$ years and their disease duration ranged from 1 year to 25 years with a mean of $8.15 \pm 6.05$ years. Eight patients were smokers.

All patients gave their informed consent prior to their inclusion. Patients with any associated disease which might have affected BMI (e.g., celiac disease) were excluded from this study. The study was approved by the local ethics committee and it conforms to the standards currently applied in Cairo University Teaching Hospitals.

Patients described their tobacco use, and submitted written estimates for their pain (0-10 scale) using a visual analog scale (VAS) (11). Overall functional status was estimated according to the Multidimensional Health Assessment Questionnaire (MD-HAQ; 0-3 scale) (12).

We recorded the presence of erosions on radiographs (13), the presence of subcutaneous nodules (SCN), 28 tender joint count (TJC) scores, 28 swollen joint count (SJC) scores, erythrocyte sedimentation rate (ESR; mm/hour), and physicians' global assessment (PhGA) (14).

The composite DAS28 score was computed as DAS28 $=[0.56 *$ sqrt (number of tender joints) $+0.28 *$ sqrt (number of swollen joints) $+0.70 * \ln (\mathrm{ESR})+0.014 *$ (patient global score)] (15).

Body mass index (BMI) was calculated as a continuous variable, from the measured heights and weights, as weight in kilograms divided by the square of the height in meters. BMI values were also categorized into the widely used underweight $(<18.5 \mathrm{~kg} /$ $\mathrm{m}^{2}$ ), normal $\left(18.5-24.9 \mathrm{~kg} / \mathrm{m}^{2}\right)$, overweight $\left(25-29.9 \mathrm{~kg} / \mathrm{m}^{2}\right)$ and obese $\left(\geq 30 \mathrm{~kg} / \mathrm{m}^{2}\right)$ categories, based on the 1998 clinical guidelines (16). In our study, the patients were divided according to their BMI into two groups: Group I including the underweight and normal BMI categories and Group II including overweight and obese BMI categories.

Regarding laboratory measures; serum collected was analyzed to determine rheumatoid factor (RF; positivity at $\geq 15 \mathrm{IU} / \mathrm{mL}$ ) and ESR.

In this study, all patients were on current disease modifying anti-rheumatic drugs (DMARD) therapy (methotrexate, leflunomide or sulfasalazine), $48 \%$ of patients were on current low dose steroid $(3.28 \pm 4.13 \mathrm{mg} /$ day $)$, but none of them received biological treatment before or during time of the study.

\section{Statistical analysis}

An IBM compatible PC was used to store and analyze the data. Calculations were done by means of a software statistics package, namely SPSS 13 for Windows (SPSS, Chicago, IL, USA).

Results were expressed as mean \pm S.D. Comparisons were made by the unpaired $t$ test. Chi-square test was used for qualitative data. $\mathrm{P}$ values lower than 0.05 were considered statistically significant.

\section{RESULTS}

Group I included the underweight and normal BMI categories. It represented 30.5\% $(n=32)$ of the enrolled patients. Group II included the overweight and obese BMI categories. It represented $69.5 \%(n=73)$ of the enrolled patients.

Regarding the two groups, there were statistically significant differences in the following parameters: SJC $(\mathrm{p}=0.006)$, presence of erosions $(\mathrm{p}=0.006)$, DAS28 $(\mathrm{p}=0.016)$, and PhGA $(\mathrm{p}=0.007)$. There was no statistically significant difference between the two groups regarding each of the following: age, gender, smoking, disease duration, TJC, SCN, HAQ, VAS, ESR, RF and steroid cumulative dose as shown in Tables I-III.

Body mass index (BMI) was significantly positively correlated with age $(p=0.046)$, but was significantly negatively correlated with disease duration $(\mathrm{p}=0.029)$ and PhGA $(\mathrm{p}=0.042)$. 
Table I - Comparison between Group 1 (underweight and normal) and Group 2 (overweight and obese) regarding their epidemiological data.

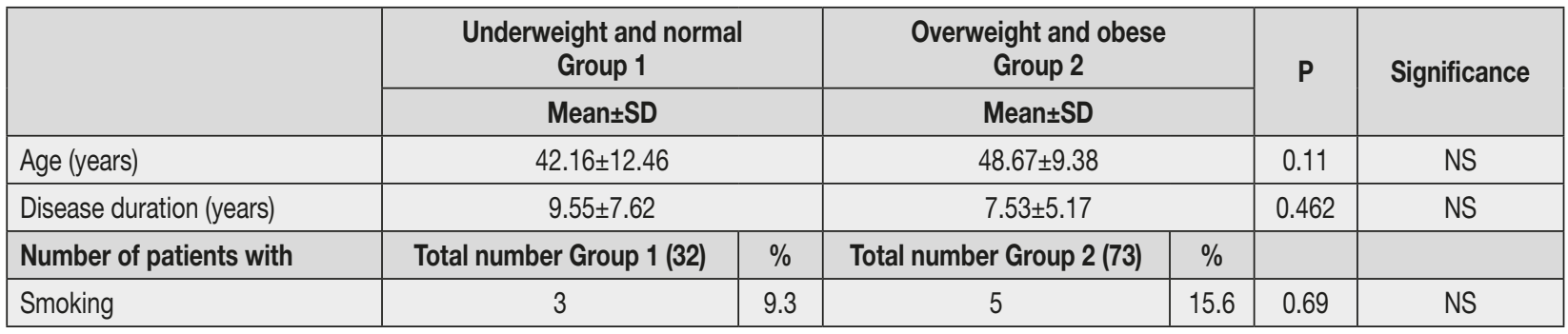

Table II - Comparison between Group 1 (underweight and normal) and Group 2 (overweight and obese) regarding their clinical and treatment data.

\begin{tabular}{|l|c|c|c|}
\hline & Group 1 $(\mathbf{n}=32)$ & Group 2 $(\mathbf{n}=73)$ & P \\
\hline SJC & $7.56 \pm 4.31$ & $5.22 \pm 4.04$ & $0.006^{*}$ \\
\hline TJC & $8.53 \pm 4.91$ & $7.08 \pm 4.58$ & 0.141 \\
\hline PhGA & $4.59 \pm 1.95$ & $3.41 \pm 2.6$ & $0.007^{*}$ \\
\hline HAQ & $7.28 \pm 4.75$ & $6.19 \pm 4.05$ & 0.262 \\
\hline VAS & $6.06 \pm 1.83$ & $5.38 \pm 2.21$ & 0.167 \\
\hline DAS 28 & $5.57 \pm 0.93$ & $5.05 \pm 1.04$ & 0.016 \\
\hline Steroid cumulative dose in $\mathrm{mg}$ & $8,299.23 \pm 10,824.16$ & $5,252.09 \pm 10,599.17$ & 0.084 \\
\hline Subcutaneous nodules & $10(31.2 \%)$ & $22(30.1 \%)$ & 1.00 \\
\hline
\end{tabular}

BMI, body mass index; SJC, Swollen joint count; TJC, tender joint count; DGA, doctors' global assessment; $\mathrm{HAQ}$, health assessment questionnaire; VAS, visual analogue scale; DAS 28, disease activity score including 28 joints. *Denotes statistical significance $(p<0.05)$.

Table III - Comparison between Group 1 (underweight and normal) and Group 2 (overweight and obese) regarding their laboratory and radiological data.

\begin{tabular}{|c|c|c|c|c|c|c|}
\hline & \multicolumn{2}{|c|}{$\begin{array}{l}\text { Underweight and normal } \\
\text { Group } 1\end{array}$} & \multirow{2}{*}{\multicolumn{2}{|c|}{$\begin{array}{c}\text { Overweight and obese } \\
\text { Group } 2 \\
\text { Mean } \pm \text { SD }\end{array}$}} & \multirow[t]{2}{*}{$\mathbf{P}$} & \multirow[t]{2}{*}{ Significance } \\
\hline & Mean \pm SD & & & & & \\
\hline ESR (mm/hour) & \multicolumn{2}{|l|}{$55.28 \pm 26.66$} & \multicolumn{2}{|l|}{$46.40 \pm 20.14$} & 0.25 & NS \\
\hline Number of patients with & Total number Group 1 (32) & $\%$ & Total number Group 2 (73) & $\%$ & & \\
\hline Positive RF & 29 & 90.6 & 62 & 84.9 & 0.543 & NS \\
\hline Erosions (in X-ray) & 28 & 87.5 & 44 & 60.2 & 0.006 & Significant \\
\hline
\end{tabular}

ESR, erythrocyte sedimentation rate; RF, rheumatoid factor.

\section{DISCUSSION}

The relation between BMI and RA is controversial. Fassio and colleagues (17) stated that mean BMI was statistically lower in RA patients $(\mathrm{P}<0.05)$. However, Albrecht et al. (18), stated, that compared to the general population, a higher prevalence of obesity was observed in all RA cohorts.

Body mass index (BMI) can be considered as a simple anthropometric measure that provides a marker of nutritional status and was shown to interact with radiographic joint damage in a large cohort of patients with early RA (19). Even more, some reports consider low BMI as independent predictor of poor radiological outcome (7). Although obesity is generally considered to be a risk factor for proinflammatory disorders such as atherosclerosis and diabetes, in RA the story may be different. In this study we found that the increase in BMI 
is associated with less joint damage in the form of decreased frequency of erosions $(p=0.006)$. Similar results were found by many other authors $(7,19-21)$. This may be accepted when we know that adipocytes were found to be tightly packed in the synovial tissue of obese patients. This lowers the occurrence of crosslink markers in the synovial tissue of obese RA patients and in their urine, reflects inhibited collagen degradation and supports the clinical finding of decreased radiographic joint damage (22). However, the exact physiologic mechanisms underlying the beneficial effects of high body mass or body fat are still widely unknown (23).

In this study, the swollen joints count was higher in the low BMI group (group I) and the difference between the two groups was statistically significant $(p=0.006)$. Similar results were found by other investigators $(24,25)$. However, other studies $(19,21)$ found no association between BMI and SJC.

The significant negative correlation between BMI and the disease duration in our results ( $\mathrm{p}=0.029)$ and in another study (26) may also imply that longstanding RA, especially when active and associated with joint destruction, is associated with low BMI.

We also found that disease activity was higher in group 1 (those with lower BMI) $(p=0.016)$. Similar results were reported by other investigators (27), who stated that lower DAS28 was associated with an increased BMI. Moreover, it was reported that low body mass index is a risk factor for poor long term outcomes in RA (28).

On the other hand, other authors found that high BMI was associated with increased disease activity in RA $(29,18,30)$, and that overweight at diagnosis significantly decreases the chance of achieving good disease control during the early phase of RA (31). However, a major difference between our study and the previous two studies is that in these studies the authors studied early RA patients with disease duration $\leq 12$ months, but in our study the patients had established RA with disease duration $>12$ months, allowing the impact of obesity on the disease process to be apparent.

Others, too, reported that both very low and very high BMI and body fat associate independently with increased disease activity and physical dysfunction (32), and that ethnicity and the different environmental factors may affect the relation between BMI and RA (26).

Although HAQ was higher in group I as compared to group II, the difference between the two groups was not statistically significant. This may be because a BMI $>30 \mathrm{~kg} / \mathrm{m}^{2}$ itself is associated with a decreased physical functioning in healthy obese people (33).

In our opinion, the conflicting reports about RA and BMI may be explained by objective differences in different studies [studying impact of RA on BMI or the reverse, studying the role of BMI in RA pathogenesis or the protective effect of BMI in RA, the type of RA patients included in the study (early or late)]. Thus, the relationship between BMI and clinical activity in RA needs to be approached with further studies with higher methodological quality to obtain solid results concerning any such relationship.

\section{CONCLUSIONS}

Low BMI in longstanding RA patients may indicate more active and erosive disease and it may be considered as a poor prognostic factor in longstanding RA.

\section{Limitations}

The small number of patients included in this study, and the absence of biological treatment in our patients, represent the most important limitations in our study. Moreover, we think that the use of ACPA and CRP in further studies may be stronger predictors for bone damage rather than ESR or RF.

Contributions: all authors approved entirely the submitted material and contributed actively to the study.

Conflicts of interest: none. 


\section{REFERENCES}

1. Scott DL, Wolfe F, Huizinga TW. Rheumatoid arthritis. Lancet. 2010; 376: 1094-108.

2. Symmons DP, Bankhead CR, Harrison BJ, et al. Blood transfusion, smoking, and obesity as risk factors for the development of rheumatoid arthritis: results from a primary care-based incident case-control study in Norfolk, England. Arthritis Rheum. 1997; 40: 1955-61.

3. García-Poma A, Segami MI, Mora CS, et al. Obesity is independently associated with impaired quality of life in patients with rheumatoid arthritis. Clin Rheumatol. 2007; 26: 1831-5.

4. Escalante A, Haas RW, del Rincon I. Paradoxical effect of body mass index on survival in rheumatoid arthritis: role of comorbidity and systemic inflammation. Arch Intern Med. 2005; 165: 1624-9.

5. Tekaya R, Sahli H, Zribi S, et al. Obesity has a protective effect on radiographic joint damage in rheumatoid arthritis. Tunis Med. 2011; 89: 462-5.

6. Binymin K, Herrick AL, Carlson GL, Hopkins S. The effect of disease activity on body composition and resting energy expenditure in patients with rheumatoid arthritis. J Inflamm Res. 2011; 4: 61-6.

7. Kaufmann J, Kielstein V, Kilian S, et al. Relation between body mass index and radiological progression in patients with rheumatoid arthritis. J Rheumatol. 2003; 30: 2350-5.

8. Stavropoulos-Kalinoglou A, Metsios GS, Koutedakis Y, et al. Redefining overweight and obesity in rheumatoid arthritis patients. Ann Rheum Dis. 2007; 66: 1316-21.

9. Choe JY, Bae J, Lee H. Lack association of body mass index with disease activity composites of rheumatoid arthritis in Korean population: cross-sectional observation. ClinRheumatol. 2013 [Epub ahead of print].

10. Arnett FC, Edworthy SM, Bloch DA, et al. The American Rheumatism Association 1987 revised criteria for the classification of rheumatoid arthritis. Arthritis Rheum. 1988; 31: 315-24.

11. Sriwatanakul K, Kelvie W, Lasagna L, et al. Studies with different types of visual analog scales for measurement of pain. Clin Pharmacol Ther. 1983; 34: 234-9.

12. Pincus T, Sokka T, Kautiainen H. Further development of a physical function scale on a multidimensional health assessment questionnaire for standard care of patients with rheumatic diseases. J Rheumatol. 2005; 32: 1432-9.

13. Larsen A. How to apply Larsen score in evaluating radiographs of rheumatoid arthritis in long-term studies. J Rheumatol. 1995; 22: 1974-5.
14. Aletaha D, Smolen JS. The Simplified Disease Activity Index (SDAI) and Clinical Disease Activity Index (CDAI) to monitor patients in standard clinical care. Best Pract Res Clin Rheumatol. 2007; 21: 663-75.

15. Prevoo MLL, van't Hof MA, Kuper HH, et al. Modified disease activity scores that include twenty-eight-joint counts: development and validation in a prospective longitudinal study of patients with rheumatoid arthritis. Arthritis Rheum. 1995; 38: 44-8.

16. Global Database on Body Mass Index. BMI Classification. Geneva: World Health Organization; 2006. [Retrieved July 27, 2012].

17. Fassio A, Idolazzi L, Jaber MA, et al. The negative bone effects of the disease and of chronic corticosteroid treatment in premenopausal women affected by rheumatoid arthritis. Reumatismo 2016; 68: 65-71.

18. Albrecht K, Richter A, Callhoff J, et al. Body mass index distribution in rheumatoid arthritis: a collaborative analysis from three large German rheumatoid arthritis databases. Arthrit Res Ther. 2016; 18: 149.

19. Westhoff G, Rau R, Zink A. Radiographic joint damage in early rheumatoid arthritis is highly dependent on body mass index. Arthrit Rheum. 2007; 56: 3575-82.

20. Van der Helm-van, Mil AH, van der Kooij SM, et al. A high body mass index has a protective effect on the amount of joint destruction in small joints in early rheumatoid arthritis. Ann Rheum Dis. 2008; 67: 769-74.

21. Caplan L, Davis LA, Bright CM, et al. Body mass index and the rheumatoid arthritis swollen joint count: an observational study. Arthr Care Res. 2013; 65: 101-6.

22. Kaufmann J, Voigt A, Müller A. Synovial collagen II degradation correlates inversely with the body mass index in rheumatoid arthritis. $\mathrm{Z}$ Rheumatol. 2001; 60: 1/77.

23. Tremollieres FA, Pouilles JM, Ribot C. Vertebral postmenopausal bone loss is reduced in overweight women: a longitudinal study in 155 early postmenopausal women. J Clin Endocrinol Metab. 1993; 77: 683-6.

24. Roubenoff R, Roubenoff RA, Ward LM, et al. Rheumatoid cachexia: depletion of lean body mass in rheumatoid arthritis. Possible association with tumor necrosis factor. J Rheumatol. 1992; 19: 1505-10.

25. Arshad A, Rashid R, Benjamin K. The effect of disease activity on fat-free mass and resting energy expenditure in patients with rheumatoid arthritis versus non inflammatory arthropathies/soft tissue rheumatism. Mod Rheumatol. 2007; 17: 470-5.

26. Jawaheer D, Olsen J, Lahiff M, et al. Gender, body mass index and rheumatoid arthritis disease activity: results from the QUEST-RA study. Clin Exp Rheumatol. 2010; 28: 454-61. 
27. Jurgens MS, Jacobs JW, Geenen R, et al. Increase of body mass index in a tight controlled methotrexate-based strategy with prednisone in early rheumatoid arthritis: side effect of the prednisone or better control of disease activity? Arthritis Care Res (Hoboken). 2013; 65: 88-93.

28. Baker JF, Cannon GW, Ibrahim S, et al. Predictors of longterm changes in body mass index in rheumatoid arthritis. J Rheumatol. 2015; 42: 920-7.

29. Ajeganova S, Andersson ML, Hafström I. Association of obesity with worse disease severity in rheumatoid arthritis as well as with comorbidities: a long-term follow up from disease onset. Arthri Care Res. 2013; 65: 78-87.

30. Liu Y, Hazlewood GS, Kaplan GG, et al. Impact of obesity on remission and disease activ- ity in rheumatoid arthritis: a systematic review and meta-analysis. Arthritis Care Res (Hoboken). 2017; 69: 157-65.

31. Sandberg ME, Bengtsson C, Källberg H, et al. Overweight decreases the chance of achieving good response and low disease activity in early rheumatoid arthritis. Ann Rheum Dis. 2013 [Epub ahead of print].

32. Stavropoulos-Kalinoglou A, Metsios GS, Panoulas VF, et al. Underweight and obese states both associate with worse disease activity and physical function in patients with established rheumatoid arthritis. Clin Rheumatol. 2009; 28: 439-44.

33. Surtees PG, Wainwright NW, Khaw KT. Obesity, confidant support and functional health: cross-sectional evidence from the EPIC-Norfolk cohort. Int J Obes Relat Metab Disord. 2004; 28: 748-58. 